\title{
$\gamma$-Protocadherins Are Targeted to Subsets of Synapses and Intracellular Organelles in Neurons
}

\author{
Greg R. Phillips, ${ }^{1}$ Hidekazu Tanaka, ${ }^{3}$ Marcus Frank, ${ }^{1,4}$ Alice Elste, ${ }^{1}$ Lazar Fidler, ${ }^{1}$ Deanna L. Benson, ${ }^{1}$ and \\ David R. Colman ${ }^{1,2}$ \\ ${ }^{1}$ Fishberg Research Center for Neurobiology, Mount Sinai School of Medicine, New York, New York 10029, ${ }^{2}$ Montreal Neurological Institute, Montreal, \\ Quebec H3A 2B4, Canada, ${ }^{3}$ Department of Pharmacology, Osaka University School of Medicine, 2-2 Yamada-oka, Osaka, Japan, and ${ }^{4}$ Department of \\ Molecular Embryology, Max-Planck Institute of Immunobiology, 79108 Freiburg, Germany
}

The clustered protocadherins (Pcdhs) comprise $>50$ putative synaptic recognition molecules that are related to classical cadherins and highly expressed in the nervous system. Pcdhs are organized into three gene clusters $(\alpha, \beta$, and $\gamma)$. Within the $\alpha$ and $\gamma$ clusters, three exons encode the cytoplasmic domain for each Pcdh, making these domains identical within a cluster. Using an antibody to the Pcdh- $\gamma$ constant cytoplasmic domain, we find that all interneurons in cultured hippocampal neurons express high levels of Pcdh- $\gamma$ s in a nonsynaptic distribution. In contrast, only $48 \%$ of pyramidal-like cells expressed appreciable levels of these molecules. In these cells, Pcdh- $\gamma$ s were associated with a subset of excitatory synapses in which they may mediate presynaptic to postsynaptic recognition in concert with classical cadherins. Immunogold localization in hippocampal tissue showed Pcdh- $\gamma s$ at some synapses, in nonsynaptic plasma membranes, and in axonal and dendritic tubulovesicular structures, indicating that they may be exchanged among synapses and intracellular compartments. Our results show that although Pcdh- $\gamma$ s can be synaptic molecules, synapses form lacking Pcdh- $\gamma \mathrm{s}$. Thus, Pcdh- $\gamma s$ and their relatives may be late additions to the classical cadherin-based synaptic adhesive scaffold; their presence in intracellular compartments suggests a role in modifying synaptic physiology or stability.

Key words: adhesion; synaptogenesis; postsynaptic density; pyramidal cells; interneurons; signaling

\section{Introduction}

Recognition/adhesion molecules, including classical cadherins, neurexins/neuroligins, nectins, and Eph receptor tyrosine kinases are concentrated at CNS synapses (Cantallops and Cline, 2000). Each can be envisioned as a "bridge" across the synaptic cleft pairing recognition events to anchorage of submembranous synaptic components. The classical cadherins are also thought to contribute to the formation of subtypes of synaptic connections via their homophilic binding capacity (Fannon and Colman, 1996). Thus, the composition of the trans-synaptic scaffold probably differs at individual synapses which may confer upon each synapse a unique physiology.

The protocadherins (Pcdhs), related to classical cadherins, are putative trans-synaptic recognition molecules (Kohmura et al., 1998; Wu and Maniatis, 1999). Genes for Pcdhs are organized into clusters (termed $\alpha, \beta$, and $\gamma$ ) with 14-22 Pcdh genes per cluster (Wu and Maniatis, 1999; Wu et al., 2001). Only the $\alpha$ and $\gamma$ clusters have been characterized definitively. Within these clusters, common exons encode the cytoplasmic domain for each Pcdh, making the cytoplasmic domains of Pcdhs within a cluster identical. The variable and constant exons combine by cissplicing of mRNA generated from promoters upstream from

Received Nov. 12, 2002; revised April 10, 2003; accepted April 14, 2003.

This work was supported by National Institutes of Health Grant (NIH) NS041687 and a New York State Spinal Cord Injury Trust Award (C016883) (D.R.C.), NIH Grant NS37731 (D.L.B.), and a grant-in-aid for advanced brain science project from the Ministry of Education, Culture, Sports, and Sciences and Technology of Japan (H.T.).

G.R.P. and H.T. contributed equally to this study.

Correspondence should be addressed to D. R. Colman, Montreal Neurological Institute, 3801 University Avenue, Montreal, Quebec H3A 2B4, Canada. E-mail: david.colman@mcgill.ca.

Copyright $\odot 2003$ Society for Neuroscience $\quad$ 0270-6474/03/235096-09\$15.00/0 each Pcdh gene (Tasic et al., 2002; Wang et al., 2002a). Thus, a diversity of molecules are produced, presumably with different specificity, that can bind to the same submembranous elements at the synapse. Consistent with a role in neural recognition, neurons of the same type and cellular layer express different repertoires of Pcdh- $\gamma$ s (Wang et al., 2002b; M. Frank and D. R. Colman, unpublished observations).

Pcdh extracellular domains exhibit characteristics of calciumdependent adhesion molecules (Obata et al., 1995; Kohmura et al., 1998; Wu and Maniatis, 1999), but their cytoplasmic domains bear no similarity to those of classical cadherins. Classical cadherins form an intracellular complex with the catenins that links cadherins to the actin cytoskeleton (Aberle et al., 1996) and to other synaptic proteins (Nishimura et al., 2002). Blockade of the interaction between the cadherin cytoplasmic domain and catenins disrupts the formation and alignment of presynaptic and postsynaptic components in cultured hippocampal neurons (Togashi et al., 2002). Thus, although it is possible that the Pcdhs are adhesive molecules (Obata et al., 1995), the Pcdh- $\alpha$ and $-\gamma$ constant cytoplasmic domains must connect to different submembranous components, suggesting a role distinct from that of the classical cadherins.

We asked whether Pcdh- $\gamma$ s exhibit properties consistent with a role in adhesion/recognition during synaptogenesis. Pcdh- $\gamma \mathrm{s}$ were expressed in a subset of neurons in culture, interneuronal cells and some pyramidal-like neurons, whereas many pyramidal-like neurons forming excitatory synapses did not express appreciable levels of these molecules. In the subset of Pcdh$\gamma$-positive pyramidal-like cells, Pcdh- $\gamma$ s were found at certain excitatory synapses. Immunoelectron microscopy showed Pcdh- $\gamma \mathrm{s}$ 
in the presynaptic and postsynaptic membranes of some synapses and nonsynaptic membranes, as well as within intracellular tubulovesicular organelles. Our results show that Pcdh- $\gamma$ s are likely to mediate trans-synaptic interactions but are not required for initial events in synaptogenesis as are classical cadherins. We suggest a model in which Pcdhs modify existing synaptic adhesive scaffolds only at synapses formed between two neurons that express the same Pcdh.

\section{Materials and Methods}

Antibodies. Antibodies to the constant cytoplasmic domain of the Pcdh- $\gamma$ s were produced by immunizing rabbits with a fusion protein consisting of the entire Pcdh- $\gamma$ constant cytoplasmic domain fused to glutathione $S$-transferase (GST-Pcdh- $\gamma$-cyto). For affinity purification, residues $1-35$ of the constant cytoplasmic domain were produced as a separate GST fusion protein, cleaved from the GST moiety using thrombin, and purified by gel filtration. This smaller fragment of the Pcdh- $\gamma$ cytoplasmic domain was then coupled to cyanogen bromide-activated Sepharose (Pharmacia), and the resulting matrix was used to affinity purify antibodies from immunoreactive sera.

Monoclonal antibodies to postsynaptic density-95 (PSD-95) were obtained from Upstate Biotechology. A monoclonal antibody to GAD (GAD-65) that recognizes the $65 \mathrm{kDa}$ form of GAD was obtained from Developmental Studies Hybridoma Bank. Monoclonal antibodies to $\mathrm{N}$-cadherin and dynamin were obtained from BD Transduction Labs. Monoclonal antibodies to N-CAM and the kinesin heavy chain were from Chemicon.

Hippocampal neuron cultures. Hippocampal neurons were dissected from embryonic day 18 hippocampi, dissociated, and plated as described (Tanaka et al., 2000). For analysis of Pcdh- $\gamma$ expression in immature neurons, cultures were fixed after $4 \mathrm{~d}$ in vitro (DIV) and processed for immunocytochemistry. For analysis of Pcdh- $\gamma$ expression in mature neurons, cultures were fixed after $30 \mathrm{~d}$ in culture and processed.

Immunocytochemistry and immunogold electron microscopy. Cultures were stained with Pcdh- $\gamma$ antibodies alone or double labeled with monoclonal antibodies to PSD-95, GAD, or N-cadherin as described (Tanaka et al., 2000). Briefly, cultures were fixed with $4 \%$ paraformaldehyde in $\mathrm{PBS}$ for $15 \mathrm{~min}$. Cultures stained with the $\mathrm{N}$-cadherin monoclonal antibody were fixed with methanol at $-20^{\circ} \mathrm{C}$. Both methanol and paraformaldehyde fixation gave similar results with anti-Pcdh- $\gamma$-cyto. The fixed cells were washed in PBS and then permeabilized and blocked in 5\% normal goat serum, $0.1 \%$ Triton X-100 in PBS for $60 \mathrm{~min}$ at room temperature. Cultures were stained overnight in blocking buffer plus the indicated antibodies at $4^{\circ} \mathrm{C}$. After they were washed in PBS, secondary antibodies were applied in blocking buffer for $1 \mathrm{hr}$ at room temperature after which time the cultures were washed and mounted for confocal microscopy. Immunogold electron microscopy was performed as described (van Lookeren Campagne et al., 1991; Bozdagi et al., 2000).

To quantitate the number of Pcdh- $\gamma$-positive neurons in the cultures, seven 1.1-mm-diameter microscopic fields in a representative Pcdh- $\gamma /$ GAD double-label staining experiment were examined, and the number of Pcdh- $\gamma$-positive/GAD-positive, Pcdh- $\gamma$-positive/GAD-negative, and Pcdh- $\gamma$-negative/GAD-negative neurons was determined. Results were expressed as the percentage of total cells, interneurons, and noninterneurons positive for Pcdh- $\gamma \mathrm{s}$. The extent of synaptic colocalization of the Pcdh- $\gamma$ s with PSD-95 was quantified in 30 DIV hippocampal cultures. To clearly visualize synaptic puncta, the red and green channels within the merged images were individually subjected to the threshold function in Adobe Photoshop, which was set to the default value of 128 (see Fig. 4). The numbers of puncta within each channel were counted within a $30 \mu \mathrm{m}$ section of proximal dendrite in which the origin at the cell body was clearly identifiable. PSD-95-labeled synaptic sites were deemed Pcdh- $\gamma$ positive if the two channels overlapped by $>10 \%$ of the PSD-95labeled area. The number of Pcdh- $\gamma$-positive synaptic sites was counted for two to five dendrites for each cell, and an average number \pm SD was obtained for all $30 \mu \mathrm{m}$ dendritic segments counted within each condition.

Immunoblots and subcellular fractions. Subcellular membrane frac- tions were prepared as described (Huttner et al., 1983). Triton-extracted subsynaptic fractions were prepared as described (Phillips et al., 2001). Briefly, the synaptic membrane fraction (LP1) (Huttner et al., 1983) was resuspended in water, and an equal volume of $40 \mathrm{~mm}$ Tris, $\mathrm{pH} 6,1 \%$ Triton X-100 was added. Membranes were extracted on ice for $20 \mathrm{~min}$ and centrifuged at $15,000 \times g$ for $20 \mathrm{~min}$. The supernatant was reserved and the pellet was resuspended in water. A small aliquot of the pellet was

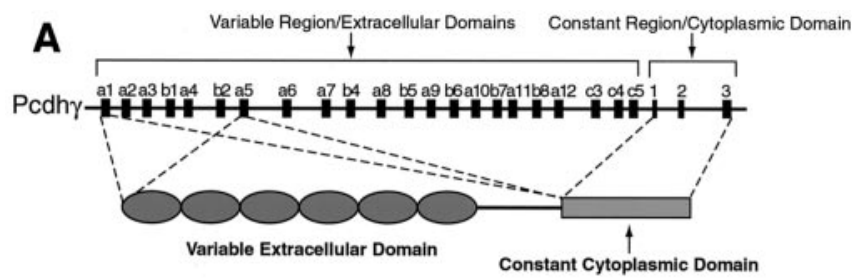

B
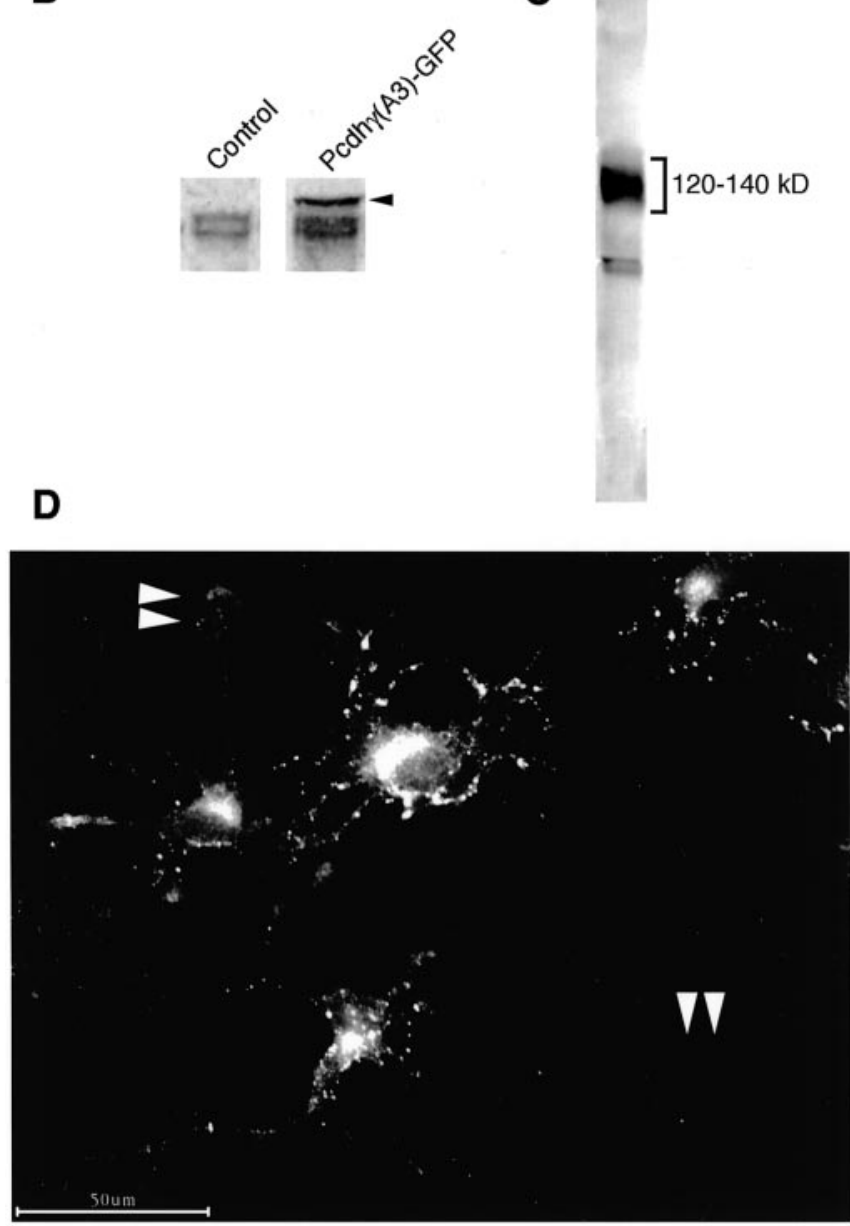

Figure 1. Production of antibodies to the constant cytoplasmic domain of Pcdh- $\gamma$ s. A, Within the Pcdh- $\gamma$ cluster, there are 22 exons each coding for a different protocadherin extracellular domain (vertical black bars). At the end of the cluster are three additional exons that code for the cytoplasmic domain for each of the protocadherin genes within the cluster. $B$, Neuro-2A cells were transfected with the CDNA for Pcdh- $\gamma$ A3 fused to GFP. Extracts from untransfected (left lane) and transfected (right lane) cells were electrophoresed and probed with affinity-purified anti-Pcdh- $\gamma$-cyto. In untransfected cells, a diffuse set of bands are observed at $\sim 120-140 \mathrm{kDa}$, which is the predicted molecular weight of the Pcdh- $\gamma \mathrm{s}$. In Pcdh- $\gamma$ A3-GFPtransfected cells, an additional band of $\sim 160 \mathrm{kDa}$ (arrowhead), which is the predicted molecular weight of the GFP fusion product, was observed. C, Detection of Pcdh- $\gamma$ s in synaptic membranes. The $120-140 \mathrm{kDa}$ Pcdh- $\gamma$ bands were detected in synaptic membranes. Minor species $(\sim 85 \mathrm{kDa})$ were also observed. D, Hippocampal cells were plated and cultured for $4 \mathrm{~d}$, fixed, and stained with anti-Pcdh- $\gamma$-cyto. At this stage, all cells expressed Pcdh- $\gamma$ s strongly in a punctate distribution. Pcdh- $\gamma$ s were not strongly expressed in growth cones (arrowheads). 
taken as the synaptic junctional fraction. To the remainder of the pellet, an equal volume of 20 mu Tris, $\mathrm{pH} 8,1 \%$ Triton X-100 was added. The junctions were extracted on ice for $20 \mathrm{~min}$ and centrifuged at $15,000 \times g$ for $20 \mathrm{~min}$. The supernatant (fraction enriched in presynaptic material) and pellet (postsynaptic densities) were recovered. All fractions were brought to $5 \%$ SDS by adding 0.25 volume of $20 \%$ SDS. Protein determination was performed by the BCA method (Pierce). Five micrograms of each fraction were electrophoresed, transferred to nitrocellulose, and probed with the indicated antibodies. Specific bands were visualized using an alkaline phosphatase secondary antibody and color reaction.

Pcdh- $\gamma-A 3$ cDNA cloning and transfection. The cDNA for mouse Pcdh- $\gamma$-A3 (see Fig. 1) was obtained by RT-PCR on the basis of published sequences (Wu et al., 2001) and sequences of the $5^{\prime}$ ends of all Pcdh- $\gamma$-As obtained by PCR on a mouse brain library template (Clontech). The amplified Pcdh$\gamma$-A3 cDNA was cloned in frame into pEGFP$\mathrm{N} 1$, yielding a green fluorescent protein (GFP) fusion construct. The integrity of the construct was verified by sequencing. This plasmid was transfected into neuro-2A cells using Superfect (Qiagen) according to recommended protocols. Permanently transfected cell lines were obtained by subcloning and subsequent selection for GFP fluorescence and expanded. Transfected and untransfected cells were lysed in $10 \%$ SDS, and the lysate was electrophoresed, transferred to nitrocellulose, and probed with affinity-purified anti-Pcdh- $\gamma$-cyto.

\section{Results}

The family of Pcdh- $\gamma$ adhesion molecules is produced by the cis-splicing of RNA from variable region exons, each encoding a different extracellular domain, to common exons located $3^{\prime}$ to the variable exons (Tasic et al., 2002; Wang et al., 2002a). The three common exons together code for a common cytoplasmic domain (Wu and Maniatis, 1999; Wu et al., 2001), making the cytoplasmic domains of all 22 Pcdh- $\gamma$ s identical (Fig. 1A). To investigate the distribution of Pcdh- $\gamma s$ in the CNS, we produced affinity-purified antibodies to the constant cytoplasmic domain of Pcdh- $\gamma$ s from mouse (anti-Pcdh- $\gamma$-cyto). We tested the antibodies for specificity against lysates from neuro-2A cells transfected with mouse Pcdh- $\gamma$-A3 fused to GFP (Pcdh- $\gamma$-A3-GFP). In untransfected cells, anti-Pcdh- $\gamma$-cyto recognized a diffuse set of bands of $\sim 120-140 \mathrm{kDa}$ (Fig. $1 B$ ). The molecular weight of these bands is in agreement with the predicted molecular weight of Pcdh- $\gamma$ s on the basis of their amino acid sequence ( $\mathrm{Wu}$ and Maniatis, 1999). The finding that neuro-2a cells express endogenous Pcdh- $\gamma s$ is in agreement with recent reports (Tasic et al., 2002). When neuro-2A cells were transfected with Pcdh- $\gamma$-A3GFP, an additional band of $\sim 160 \mathrm{kDa}$ was observed, which is, as expected, the predicted molecular weight of the fusion product (Fig. $1 B$, arrowhead). Anti-Pcdh- $\gamma$-cyto recognized a diffuse set of bands at $\sim 120-140 \mathrm{kDa}$ in immunoblots of rat brain synaptosomal membranes (Fig. $1 C$ ). We also observed minor $\sim 85 \mathrm{kDa}$ components that reacted with anti-Pcdh- $\gamma s$-cyto in synaptosome fractions (Fig. 1C) that are likely proteolytic products of fulllength Pcdh- $\gamma$ s.
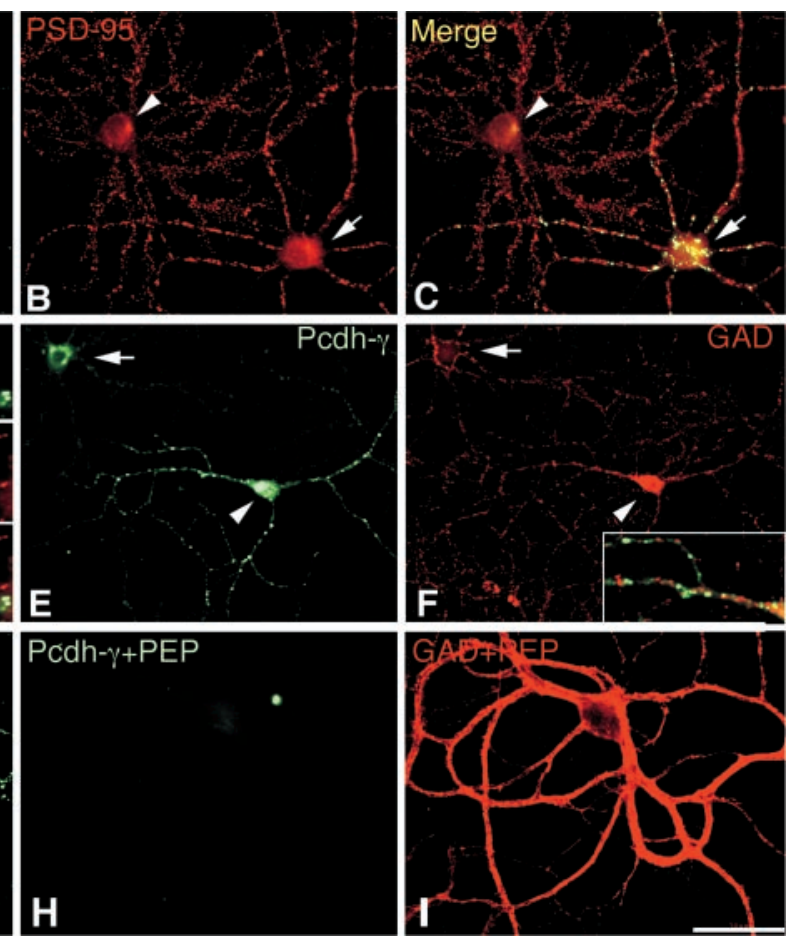

Figure 2. $\quad P c d h-\gamma s$ are expressed strongly in interneurons in mature cultures. $A-D$, Mature ( $30 \mathrm{DIV})$ cultures of hippocampa 列 I. Pcdh- $\gamma$ completely blocked the immunoreaction in interneurons of Pcdh- $\gamma(H)$ but did not affect that of GAD $(I)$. The field in $H$ and $/$ is the same. Scale bar: (in I) $A-C, E-I, 50 \mu \mathrm{m} ; D, 10 \mu \mathrm{m}$.

\section{Expression of Pcdh- $\gamma \mathrm{s}$ in cultured hippocampal neurons is heterogeneous}

We evaluated the distribution of Pcdh- $\gamma s$ in CNS by immunostaining cultured hippocampal neurons. Cultures of hippocampal neurons prepared from embryonic day 18 rat hippocampi were fixed at various time points and stained with anti-Pcdh- $\gamma$ cyto alone or double labeled with antibodies specific for excitatory synapses (anti-PSD-95) (Cho et al., 1992), inhibitory neurons and their axon terminals (GAD) (Benson et al., 1994), or other synaptic adhesion molecules (N-cadherin) (Tanaka et al., 2000).

At 4 DIV, hippocampal neurons did not yet exhibit synapses, but these neurons displayed prominent neurites and growth cones. At this stage, $100 \%$ of the cells in the culture stained equally well for Pcdh- $\gamma$ s (Fig. $1 D$ ). The majority of immunoreactivity in these cells was punctate (Fig. 1D). Growth cones, which express high levels of some adhesion molecules such as $\mathrm{N}$-cadherin (Benson and Tanaka, 1998) and L1 (Kamiguchi and Lemmon, 2000), expressed relatively low levels of Pcdh- $\gamma$ s (Fig. $1 D$, arrowheads), suggesting that Pcdh- $\gamma$ s probably do not play an important role in neurite guidance and extension during neural development.

In contrast to the uniform expression of Pcdh- $\gamma s$ in neurons cultured for $4 \mathrm{DIV}$, in neurons cultured for $30 \mathrm{DIV}$, which display mature synaptic connections, Pcdh- $\gamma$ s exhibited a heterogeneous 

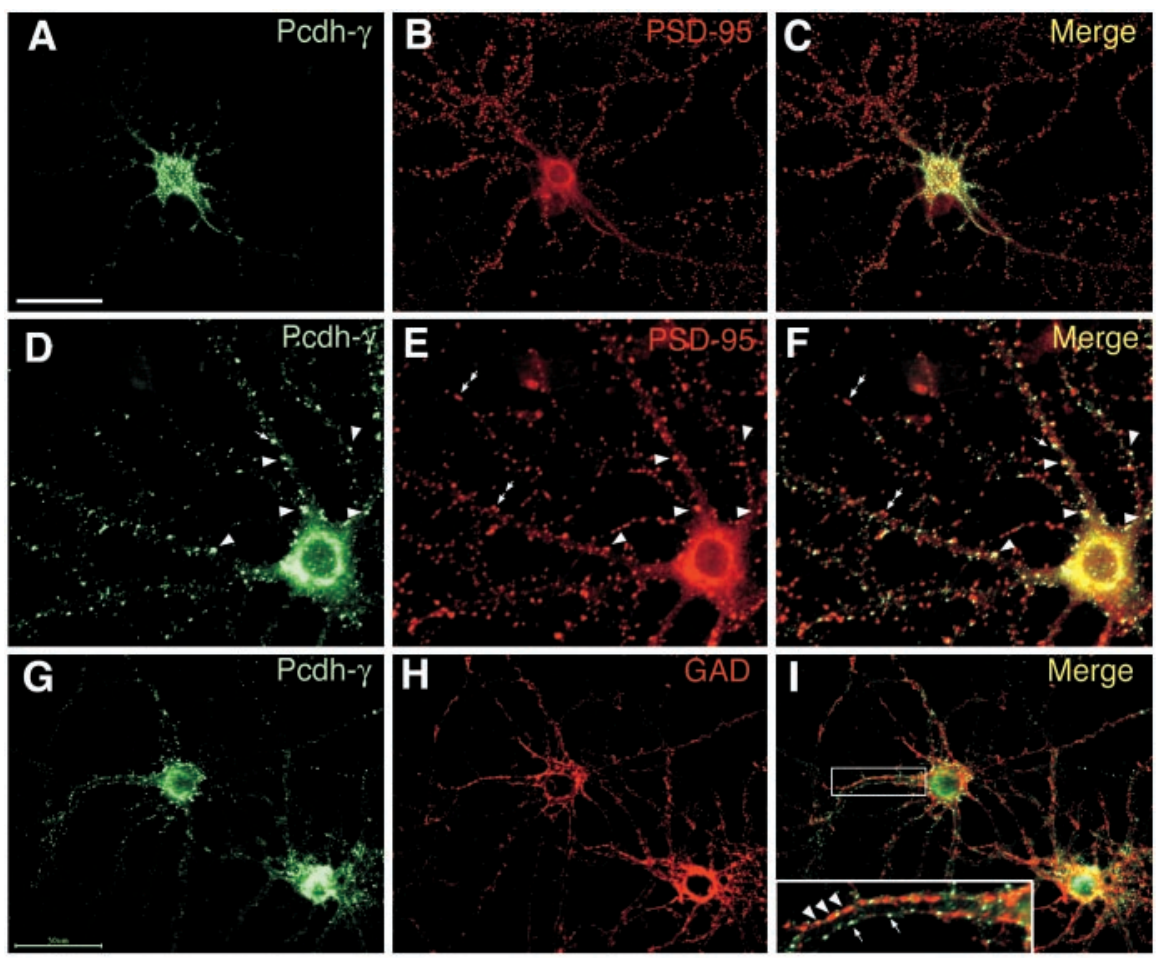

Figure 3. $P c d h-\gamma$ s are expressed in a subset of excitatory synapses. Mature cultures were double labeled with anti-Pcdh- $\gamma$-cyto and PSD-95 ( $A-F$ ) or with anti-Pcdh- $\gamma$-cyto and GAD (G-l). Only in some cases (48\%) was staining of Pcdh- $\gamma$ observed in spiny pyramidal-type cells. $A-C$, In a few of these cells, Pcdh- $\gamma$ staining appeared to be completely intracellular $(A)$ and did not overlap with PSD-95 labeling $(B, C)$, indicating that synapses can form in the absence of Pcdh- $\gamma$ s. In other spiny neurons, Pcdh- $\gamma$ staining was punctate on the dendritic surface ( $D-F)$. Double labeling with PSD-95 $(E)$ showed that Pcdh- $\gamma$ staining overlapped with some PSD-95-labeled sites ( $D-F$, arrowheads), indicating a synaptic localization. In other instances, Pcdh- $\gamma$ clusters were not synaptic ( $D, F$, single arrows). Many PSD-95-positive synaptic sites did not contain Pcdh- $\gamma s$ ( $E$, F, double arrows). G-I, Pcdh- $\gamma$-labeled synapses on excitatory cells are not inhibitory. Double label with Pcdh- $\gamma$ and GAD shows that GAD-labeled terminals $(I$, inset, arrowheads) never colocalize with Pcdh- $\gamma$-labeled sites (I, inset, arrows). Scale bar: (in A) A-l, $50 \mu \mathrm{m}$; inset, $15 \mu \mathrm{m}$. expression pattern (Fig. 2). Expression of Pcdh- $\gamma$ s was observed in an average of $55 \%$ of the cells (Fig. $2 A$, arrow), whereas many cells were unlabeled (Fig. $2 A$, arrowhead). Double labeling with PSD-95 antibodies (Fig. $2 \mathrm{~B}$ ) identified the postsynaptic specializations of excitatory synaptic connections and showed that many of the cells that expressed the highest levels of Pcdh- $\gamma \mathrm{s}$ exhibited smooth, nonspinous, dendritic surfaces, suggestive of interneurons (Fig. 2B, arrow), whereas the cells that expressed relatively low levels of Pcdh- $\gamma s$ invariably exhibited dendritic spines (Fig. $2 B$, arrowhead). When the two images were merged (Fig. $2 C, D$ ), it was revealed that the staining for Pcdh- $\gamma$ s (Fig. $2 D$, arrowhead) did not localize to PSD-95 excitatory synaptic sites on inhibitory neurons.

To conclusively determine whether high levels of Pcdh- $\gamma$ s are expressed in interneurons, we double labeled cultured neurons with anti-Pcdh- $\gamma$-cyto and anti-GAD. The strongest intracellular labeling for GAD is found within the cell bodies of inhibitory interneurons, but labeling also concentrates within inhibitory presynaptic boutons (Benson et al., 1994; Craig et al., 1994) by virtue of the palmitoylation-based trafficking of the enzyme (Kanaani et al., 2002). Thus, GAD labeling is a reliable marker for GABAergic interneurons and their terminals.

We found that $100 \%$ of the cells that expressed GAD within their cell bodies (Fig. 2F, arrowhead) also expressed Pcdh- $\gamma \mathrm{s}$ (Fig. $2 E$, arrowhead). In contrast, cells that were lightly labeled for Pcdh- $\gamma$ s (Fig. 2E, arrow) all lacked GAD in their cell body (Fig. $2 F$, arrow). Merging of the images in Figure 2, $E$ and $F$, revealed that Pcdh- $\gamma$ s did not localize to inhibitory, GAD-positive synapses on interneurons ( $F$, inset).

We bacterially expressed and purified the constant cytoplasmic domain of Pcdh- $\gamma$ s and added it to the anti-Pcdh- $\gamma$ cyto/GAD double-label reaction. In the presence of this polypeptide, the Pcdh- $\gamma$ interneuronal staining (Fig. $2 G$ ) was abolished completely (Fig. $2 H$ ), whereas the staining for GAD was unaffected (Fig. 2I).

\section{Pcdh- $\gamma$ s are expressed at a subset of excitatory synapses}

Although many spiny, excitatory cells in mature cultures did not express appreciable amounts of Pcdh- $\gamma \mathrm{s}, 48 \%$ of these cells did stain positively for Pcdh- $\gamma$ s (Fig. 3). In a few cells, expression of Pcdh- $\gamma$ s was completely nonsynaptic(Fig. 3A) and clearly did not colocalize with PSD-95labeled excitatory synapses (Fig. 3B). In the majority of spiny pyramidal-type cells that expressed Pcdh- $\gamma$ s, however, the molecules localized to some, but not all, synaptic junctions. For example, staining for Pcdh- $\gamma$ s was punctate on dendritic surfaces (Fig. 3D) and double label with PSD-95 revealed that some of the Pcdh$\gamma$-positive sites were synaptic (Fig. $3 D-F$, arrowheads). Other Pcdh- $\gamma$-positive clusters did not contain PSD-95 (Fig. 3D,F, single arrows), and many PSD-95-positive synapses did not contain Pcdh- $\gamma \mathrm{s}$ (Fig. 3E, F, double arrows).

Because high levels of Pcdh- $\gamma$ s were expressed in inhibitory interneurons, we suspected that they may also be localized to interneuron-pyramidal cell inhibitory synapses. To investigate this, we examined Pcdh- $\gamma$-positive excitatory neurons for the presence and colocalization with GADpositive inhibitory terminals (Fig. $3 G-I$ ). We found that most GAD-labeled inhibitory terminals (Fig. 3I, arrowheads), which are characteristically larger than excitatory terminals (Brunig et al., 2002), did not colocalize with Pcdh- $\gamma$ s (Fig. 3I, arrows). Thus, we conclude that both excitatory and inhibitory synapses can exist without incorporating Pcdh- $\gamma$ s. This result contrasts with studies of classical cadherins which show that these molecules are required for synaptogenesis (Togashi et al., 2002); however, Pcdh- $\gamma$-positive synapses, when found, are most likely to be of the excitatory type.

Individual Pcdh- $\gamma$-positive excitatory cells were evaluated for the extent of Pcdh- $\gamma$-positive, PSD-95-labeled synaptic sites. Because, in many cases, Pcdh- $\gamma$-positive excitatory neurons were observed in isolation, it could be that the lack of synaptic staining observed in isolated neurons results from the absence of another Pcdh- $\gamma$-positive neuron with which to form a synapse. To take into account this possibility, we also searched for Pcdh- $\gamma$-positive excitatory cell pairs and counted the percentage of Pcdh- $\gamma$-positive PSD-95-labeled synaptic sites. We found that the number of Pcdh$\gamma$-positive synapses in isolated neurons $(26 \pm 11 \%)$ was less than that in pairs of Pcdh- $\gamma$-positive neurons ( $63 \pm 23 \%$; one-tailed $t$ test; $p<0.001)$.

The increased recruitment of Pcdh- $\gamma$ s to synapses in Pcdh- $\gamma$ - 
positive cell pairs is exemplified in Figure 4. Pcdh- $\gamma$ labeling in isolated neurons (Fig. 4, green channel), albeit punctate, mostly did not colocalize PSD-95 (Fig. 4, red channel), although Pcdh- $\gamma$-positive synapses were occasionally noted (Fig. 4G, arrowheads). On the other hand, when Pcdh- $\gamma$-positive excitatory cell pairs were evaluated, broad dendritic areas of Pcdh- $\gamma$ colocalization with PSD-95 were noted (Fig. $4 B$, arrows). At higher magnification, it was found in these pairs that most of the PSD-95-labeled synaptic sites were also positive for Pcdh- $\gamma$ s (Fig. $4 \mathrm{H}$, arrowheads). Thus, recognition events across the synaptic cleft may promote the recruitment and retention of Pcdh- $\gamma$ s to subsets of excitatory synaptic junctions.

Adhesion molecules such as the classical cadherins (Yamagata et al., 1995; Fannon and Colman, 1996; Uchida et al., 1996; Inoue and Sanes, 1997) are known to be highly concentrated at synaptic junctions, but it has never been determined whether two different families of cadherin-related molecules can coexist at the same synaptic sites. We sought to determine whether Pcdh- $\gamma$ s could coexist with a member of the classical cadherin family, $\mathrm{N}$-cadherin, at the same synapse in hippocampal neurons. Hippocampal neurons were double labeled with antiPcdh- $\gamma$-cyto and a monoclonal antibody to $\mathrm{N}$-cadherin. Shown in Figure 5 is one Pcdh- $\gamma$-positive excitatory neuron that exhibits both Pcdh- $\gamma$-positive (Fig. 5A) and N-cadherin-positive (Fig. 5B) synaptic sites. Overlay of the images (Fig. 5C) shows that the two molecules colocalize to a large extent and at higher magnification (Fig. 5D) they can be seen residing at the same synaptic sites (Fig. $5 D$, arrowheads). Many other synapses contained N-cadherin but not Pcdh- $\gamma$ s. Thus multiple adhesive/recognition systems involving cadherin-related proteins can operate at an individual synaptic junction.

\section{Pcdh- $\gamma$ s are expressed at subsets of synapses and} intracellular organelles

The immunolocalization of Pcdh- $\gamma$ s in hippocampal neurons suggests that these molecules are located in synapses, but a significant proportion of Pcdh- $\gamma$ s was also nonsynaptic, as was shown recently (Wang et al., 2002b). We conducted immunogold labeling for Pcdh- $\gamma s$ in adult hippocampal tissues to more precisely localize Pcdh- $\gamma$ s in cellular structures. Hippocampal tissues were embedded by freeze substitution (van Lookeren Campagne et al., 1991), and ultrathin sections were incubated with anti-Pcdh- $\gamma$ cyto followed with $10 \mathrm{~nm}$ gold-conjugated secondary antibodies.

Strong Pcdh- $\gamma$ immunoreactivity was found on a subpopulation of tubulovesicular structures within some excitatory presynaptic terminals (Fig. 6A,B, arrowheads). These tubulovesicular structures were $\sim 50-200 \mathrm{~nm}$ in diameter and clearly distinct from synaptic vesicles (Fig. 6A, inset). Curiously, the strongest
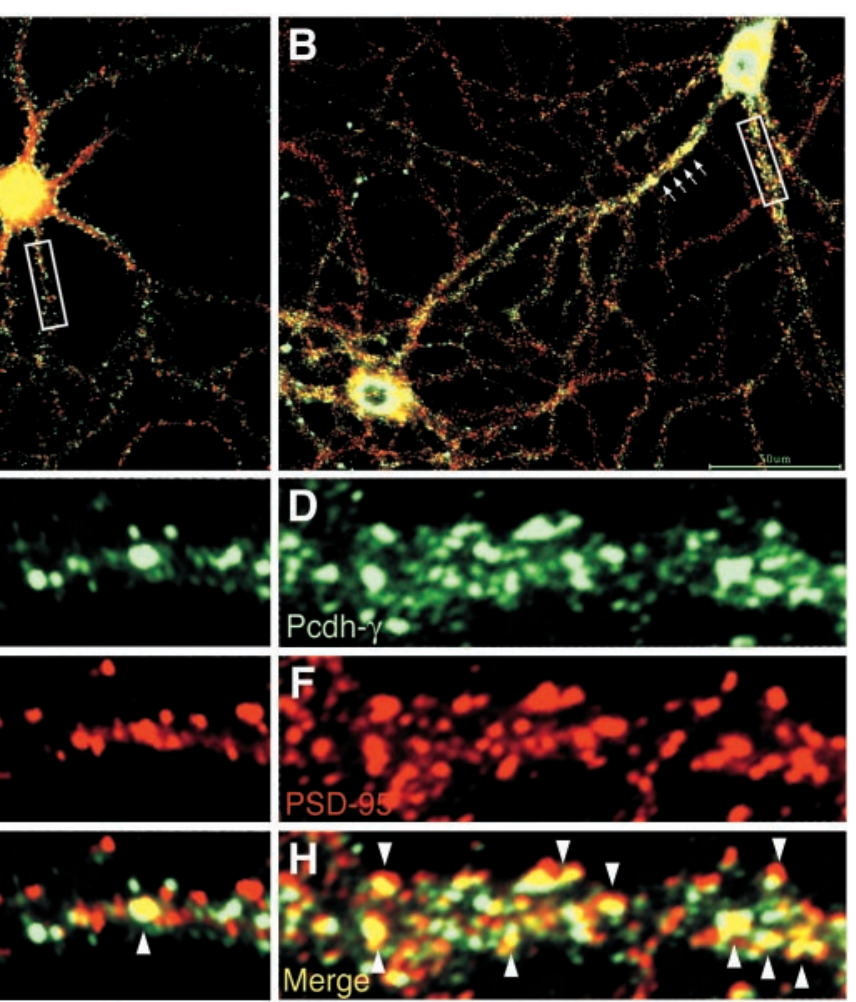

Figure 4. Increased recruitment of $P c d h-\gamma s$ to synapses in $P c d h-\gamma$-positive neuron pairs. A neuron in isolation $(A, C, E, G, I)$ or wo Pcdh- $\gamma$-positive excitatory neurons in close proximity $(B, D, F, H, J)$ were double labeled with anti-Pcdh- $\gamma$-cyto (green indicate Pcdh- $\gamma$-positive synaptic sites. In many cases, the shape of the fluorescent signal for Pcdh- $\gamma$ s closely matched that of PSD-95 ( $H$, arrowheads), indicating specific synaptic localization. I, J, Thresholded images used in the quantitation of Pcdh- $\gamma$ positive and -negative synaptic sites. Scale bar: (in I) $A, B, 50 \mu \mathrm{m} ;(-J, 10 \mu \mathrm{m}$.

presynaptic labeling for Pcdh- $\gamma$ occurred in closely associated groups of presynaptic terminals (Fig. $6 \mathrm{~A}$ ). These results suggest the possibility that these Pcdh- $\gamma$-positive terminals may represent branches of the same axon originating from a Pcdh- $\gamma$ positive neuron. The synapses formed by these Pcdh- $\gamma$-positive terminals did not appear to be of the symmetrical type expected to exist at terminals of inhibitory interneurons, however. Rather, these Pcdh- $\gamma$-positive terminals formed asymmetrical, excitatory synapses. We also found strong Pcdh- $\gamma$ labeling in some excitatory synaptic junctions (Figs. 6C-E, 7C,F). Labeling was observed on both presynaptic and postsynaptic densities or within the synaptic cleft, suggesting that Pcdh- $\gamma \mathrm{s}$, when present on the cell surface, mediate interactions between two plasma membranes. At times, Pcdh- $\gamma$ immunolabeling was concentrated at specific zones within a synapse (Fig. 6C, arrows), where electron-dense material attached at the PSD (Fig. 6C, arrowheads). Many synapses were unlabeled (Fig. 6A,B).

In addition to tubulovesicular structures in axonal endings, we found labeling of similar structures in dendritic profiles as well (Fig. $7 A-D$, arrowheads). Pcdh- $\gamma$-positive tubulovesicular structures in dendrites were of similar size $(50-200 \mathrm{~nm})$ to those found within axonal endings. Labeling for Pcdh- $\gamma$ s was also present to some extent on nonsynaptic plasma membranes (Fig. 

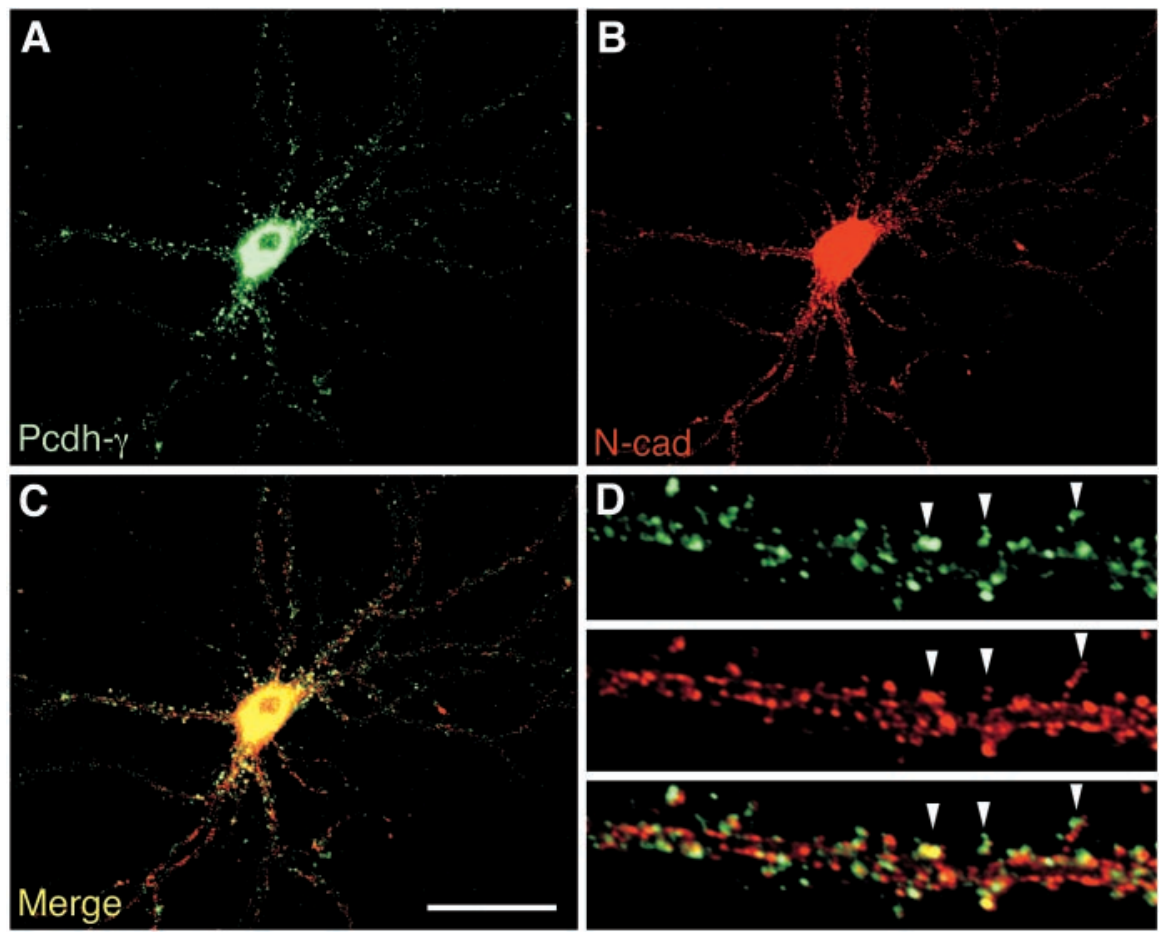

Figure 5. $\mathrm{Pcdh}-\gamma$ and $\mathrm{N}$-cadherin can coexist at synaptic junctions. Mature cultures were double labeled with anti-Pcdh- $\gamma$ cyto and anti-N-cadherin. In Pcdh- $\gamma$-expressing pyramidal type cells $(A), \mathrm{N}$-cadherin was also expressed ( $B)$. Overlay of the two images $(C, D)$ shows that $P c d h-\gamma$ and $N$-cadherin can be found at the same synaptic sites ( $D$, arrowheads). Scale bar: (in $C) A-C, 50$ $\mu \mathrm{m} ; D, 10 \mu \mathrm{m}$.

$7 D-F$, single arrows) and tended to label both opposed membranes as would be expected for a molecule engaged in cell-cell interactions. Thus Pcdh- $\gamma$ s are present on multiple membrane surfaces in CNS neurons, which may reflect a dynamic process of transport of these molecules, insertion into synaptic or nonsynaptic membranes, and possibly retrieval by endocytosis.

Subcellular fractionation was performed to confirm our observations of Pcdh- $\gamma$ localization by immunostaining. Individual membrane, vesicular, and synaptic fractions were prepared, and equal protein amounts of each fraction were electrophoresed, transferred to membranes, and probed with anti-Pcdh- $\gamma$-cyto. The enrichment of Pcdh- $\gamma$ s in each fraction was compared with that of $\mathrm{N}$-cadherin. Dynamin, the kinesin heavy chain, and synaptophysin were used as marker proteins for the fraction enriched in presynaptic material, intracellular transport vesicles, and synaptic vesicles, respectively. PSD-95 served as a marker for postsynaptic densities (Cho et al., 1992), whereas N-CAM was a marker for the fraction of proteins initially present in synaptic membrane but not associated with detergent-insoluble synaptic junctions (Phillips et al., 2001).

In the membrane fractions (Fig. 8, left panels), both Pcdh- $\gamma \mathrm{s}$ and $\mathrm{N}$-cadherin exhibited a similar pattern of enrichment in the various fractions. Relative to the postnuclear supernatant starting material (Fig. 8, PNS), both proteins were enriched in the P2 and LP1 fractions, which are synaptosomes and osmotically shocked synaptic membranes, respectively (Huttner et al., 1983). There was a significant representation of both Pcdh- $\gamma$ and N-cadherin in the P3 fraction as well as the LP2 fractions, which are composed of tubulovesicular and synaptic vesicles, respectively (Lee et al., 2001). These results suggest that Pcdh- $\gamma$ and N-cadherin are both associated with synaptic membranes as well as transport and, to a lesser extent, synaptic vesicles. The localization of
$\mathrm{N}$-cadherin to different types of transport and synaptic vesicle fractions is in agreement with previous findings (Zhai et al., 2001). In contrast to the enrichment patterns of Pcdh- $\gamma$ and $\mathrm{N}$-cadherin, the kinesin heavy chain was enriched in the P3 fraction relative to other fractions, demonstrating the relative abundance of transport vesicles in this fraction.

In contrast to N-CAM, Pcdh- $\gamma$ and $\mathrm{N}$-cadherin were both not highly represented in the Triton X-100 extractable material at pH 6 (Fig. 8, pH 6 sup) and were found primarily in the Triton X-100 insoluble material at $\mathrm{pH} 6$, which is composed of intact synaptic junctions (Fig. 8, pH 6 pel). When the junction fraction is reextracted with Triton X-100 at $\mathrm{pH} 8$, many presynaptic components such as dynamin (Fig. 8, pH 8 sup) are solubilized. A significant proportion of both Pcdh- $\gamma$ and $\mathrm{N}$-cadherin was released under these conditions (Fig. 8, pH 8 sup). A large fraction of Pcdh- $\gamma$ and $\mathrm{N}$-cadherin was also found in the Triton $\mathrm{X}-100$ pellet at $\mathrm{pH} 8$ (Fig. 8, $\mathrm{pH} 8 \mathrm{pel}$ ), which is composed of postsynaptic densities (Phillips et al., 2001) and highly enriched in PSD-95. Dynamin and kinesin were both relatively absent from the postsynaptic density fraction. Thus, these results show that Pcdh- $\gamma$ s cofractionate with presynaptic and postsynaptic material but are also found within transport and synaptic vesicles.

\section{Discussion}

Molecules that mediate the specification of different classes of synapses are most likely differentially expressed in neuronal populations and probably couple an intracellular signaling function either directly or indirectly to extracellular recognition among synaptic membranes. The clustered Pcdhs are a family of molecules that could potentially fulfill these criteria. These proteins were shown recently to be expressed differentially within a neuronal cell population (Kohmura et al., 1998; Wang et al., 2002b) and to mediate, in some cases at least, cell-cell adhesion (Obata et al., 1995). We now show that the Pcdh- $\gamma$ s are synaptic molecules that are unlikely to be required for the initial stages of synaptogenesis, as are the related classical cadherins. We also show that, when present on the cell surface, these molecules are targeted to opposing membranes at synapses or they are on nonsynaptic plasma membranes, suggestive of a role in cell-cell interactions. Furthermore, our data also suggest that a proportion of Pcdh- $\gamma \mathrm{s}$ are located in putative sorting and endosomal vesicles both presynaptically and postsynaptically. From these vesicles, Pcdh- $\gamma s$ could be inserted and retained at the synapse and could modify that synapse, if the appropriate trans-synaptic Pcdh- $\gamma$ s adhesive linkage is attained. Alternatively, Pcdh- $\gamma$ s that do not engage in adhesion at the synaptic membrane may be endocytosed and recycled internally.

The possibility exists that the Pcdh- $\gamma$ s perform functions in addition to their role as cell adhesion molecules. The evidence for this comes from the fact that the related Pcdh- $\alpha$ s (known as cadherin-related neuronal receptors or CNRs in human) were shown to interact in vitro with the extracellular matrix protein 

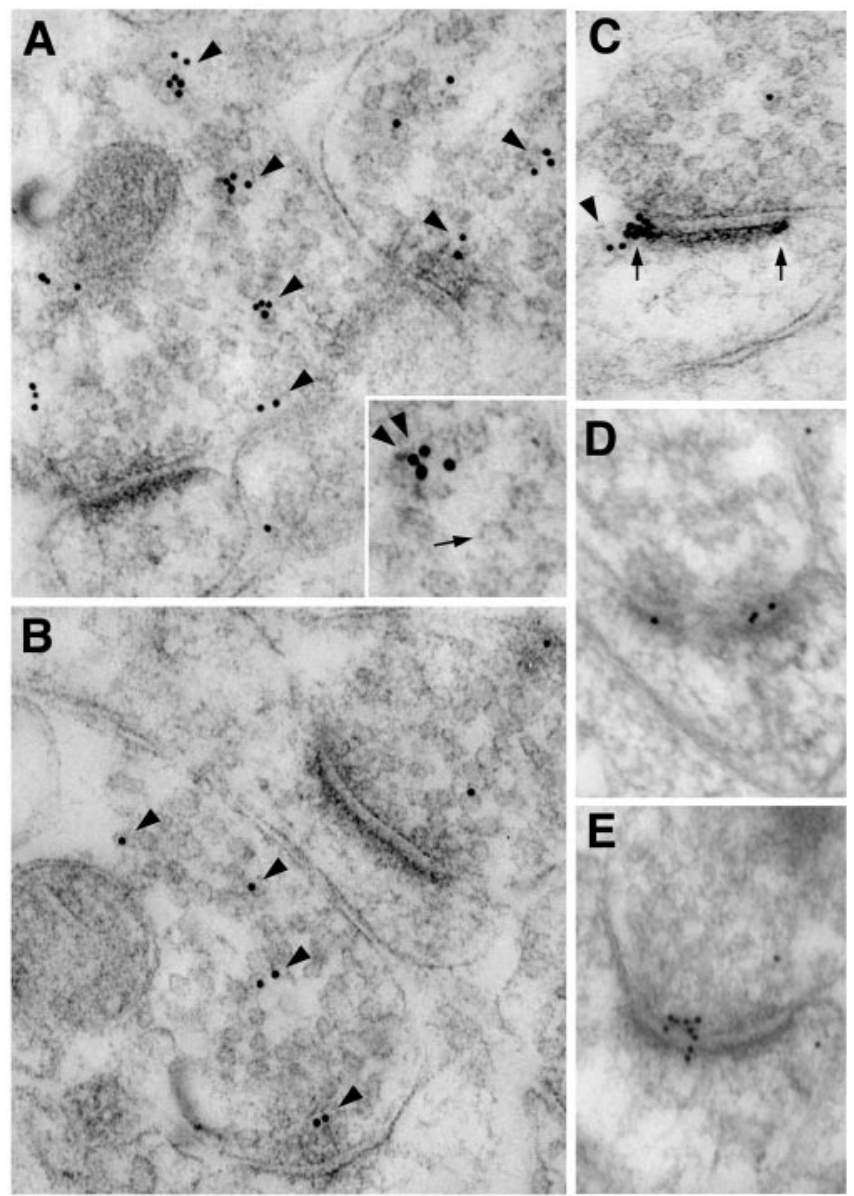

Figure 6. Pcdh- $\gamma \mathrm{s}$ are found in tubulovesicular organelles in axonal endings and at synapses. Hippocampal tissue was prepared for immunoelectron microscopy by freeze substitution embedding. Sections were incubated with anti-Pcdh- $\gamma$ affinity-pure antibodies and $10 \mathrm{~nm}$ gold-conjugated secondary antibodies. Labeling was observed in two distinct patterns. In some cases, groups $(A)$ or individual presynaptic terminals $(B)$ were positive for Pcdh- $\gamma \mathrm{s}(A, B$, arrowheads). Tubulovesicular presynaptic organelles positive for $P c d h-\gamma s$ (A, inset, arrowheads) were clearly distinct from synaptic vesicles ( $A$, inset, arrow). The Pcdh- $\gamma$-positive groups of terminals may correspond to axon branches from the same Pcdh- $\gamma$-positive neuron. $C-E$, $P c d h-\gamma$ labeling was observed at a subset of synaptic junctions. High concentrations of Pcdh- $\gamma \mathrm{s}$ were sometimes found at specific zones within a synapse ( $C$, arrows). At these zones, filaments were found to terminate at the PSD ( $C$, arrowheads).

reelin (Senzaki et al., 1999). The binding site for reelin was localized within a 29 amino acid region of the first extracellular domain (EC1) of Pcdh- $\alpha$ s that is almost completely conserved among all Pcdh- $\alpha$ family members. Within an analogous region of the Pcdh- $\gamma$ EC1 domain, there is also a highly conserved region that bears some similarity to the reelin binding site within the Pcdh- $\alpha$ s (Wu and Maniatis, 1999). Thus, it is possible that the Pcdh- $\gamma s$ will posses the same reelin-binding activity as the Pcdh$\alpha$ s. Coincidentally, both reelin and Pcdh- $\gamma$ s appear to have similar expression patterns in cultured hippocampal neurons. Both molecules are expressed primarily in GABAergic interneurons in culture (Scotti and Herrmann, 2002), with a subset of pyramidaltype cell also positive. The intracellular localization of the Pcdh- $\gamma s$ in these GABAergic cells suggests the possibility that Pcdh- $\gamma$ s could be involved in delivering reelin to the cell surface. Thus, it will be interesting to determine whether the similar expression patterns of reelin and Pcdh- $\gamma$ s in cultured hippocampal neurons is reflective of a functional interaction between these two molecules in vivo.
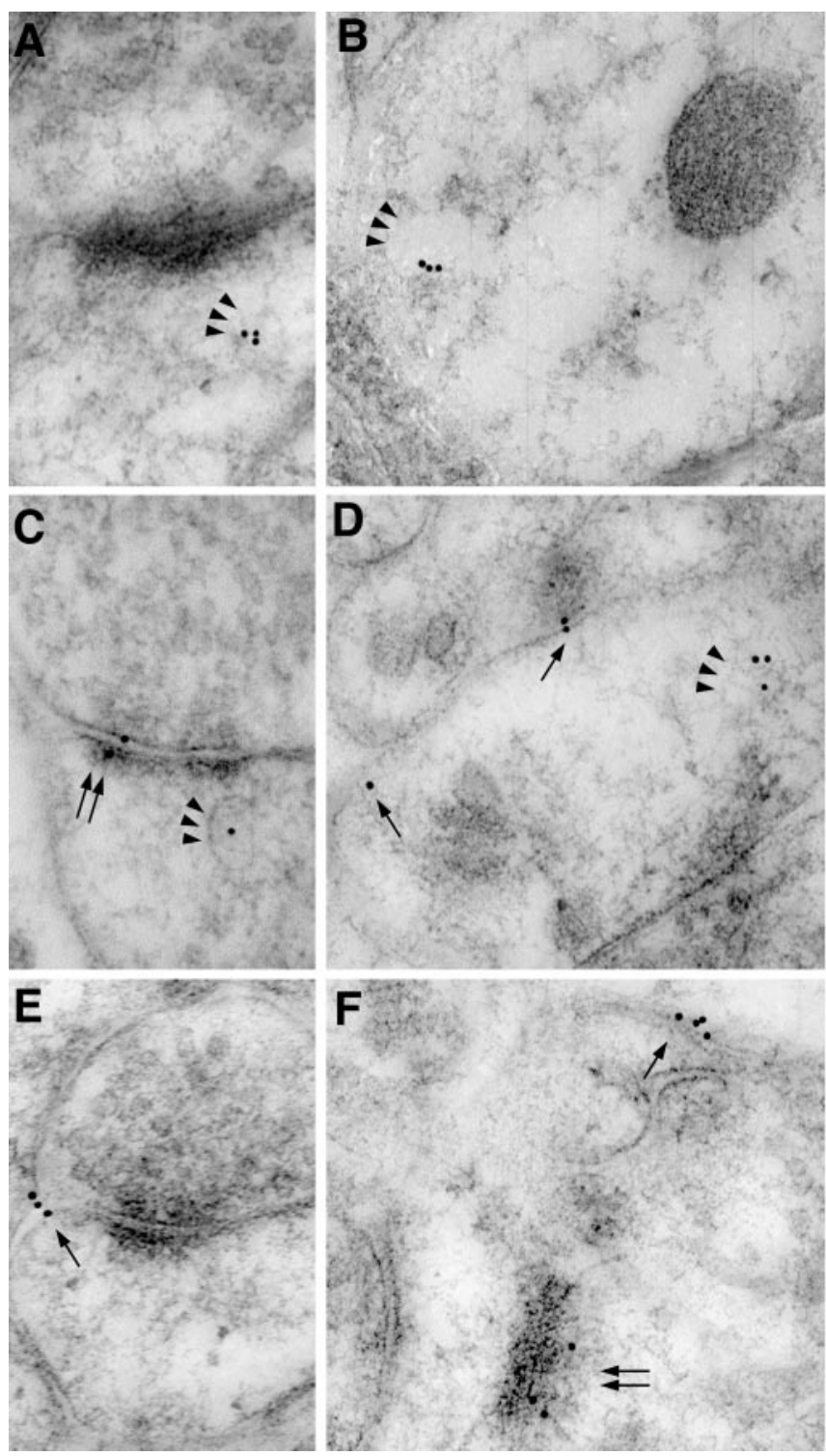

Figure 7. Pcdh- $\gamma$ s are found in tubulovesicular structures in dendritic compartments as well as in nonsynaptic membranes. Labeling for Pcdh- $\gamma \mathrm{s}$ was observed in $50-200 \mathrm{~nm}$ vesicular organelles in dendritic compartments ( $A-D$, arrowheads). Labeling was also found on nonsynaptic plasma membranes ( $D-F$, single arrows) and at synaptic junctions ( $C, F$, double arrows).

By immunoelectron microscopy, we found that in addition to synapses, Pcdh- $\gamma$ s are located in intracellular tubular organelles of $\sim 75 \mathrm{~nm}$ in diameter that are present in both axonal and dendritic compartments. The morphology of these tubules is consistent with the endocytic tubular organelles that were seen to be distributed throughout the axonal and dendritic compartments (Cooney et al., 2002). Extracellularly applied transferrin or gold particles were able to be taken up into these structures, thus demonstrating an endosomal function (Parton et al., 1992; Cooney et al., 2002). It is also likely that these tubules mediate recycling of cell surface or synaptic proteins back to the plasma membrane on the basis of the fact that clathrin-coated buds can oftentimes be found on them (Cooney et al., 2002). The presence of Pcdh- $\gamma$ s in these organelles suggests that they may be dynamically inserted and recycled at synaptic membranes.

There is some evidence that the Pcdhs, and the $\gamma$ family in particular, mediate cell-cell interactions, but whether these mol- 


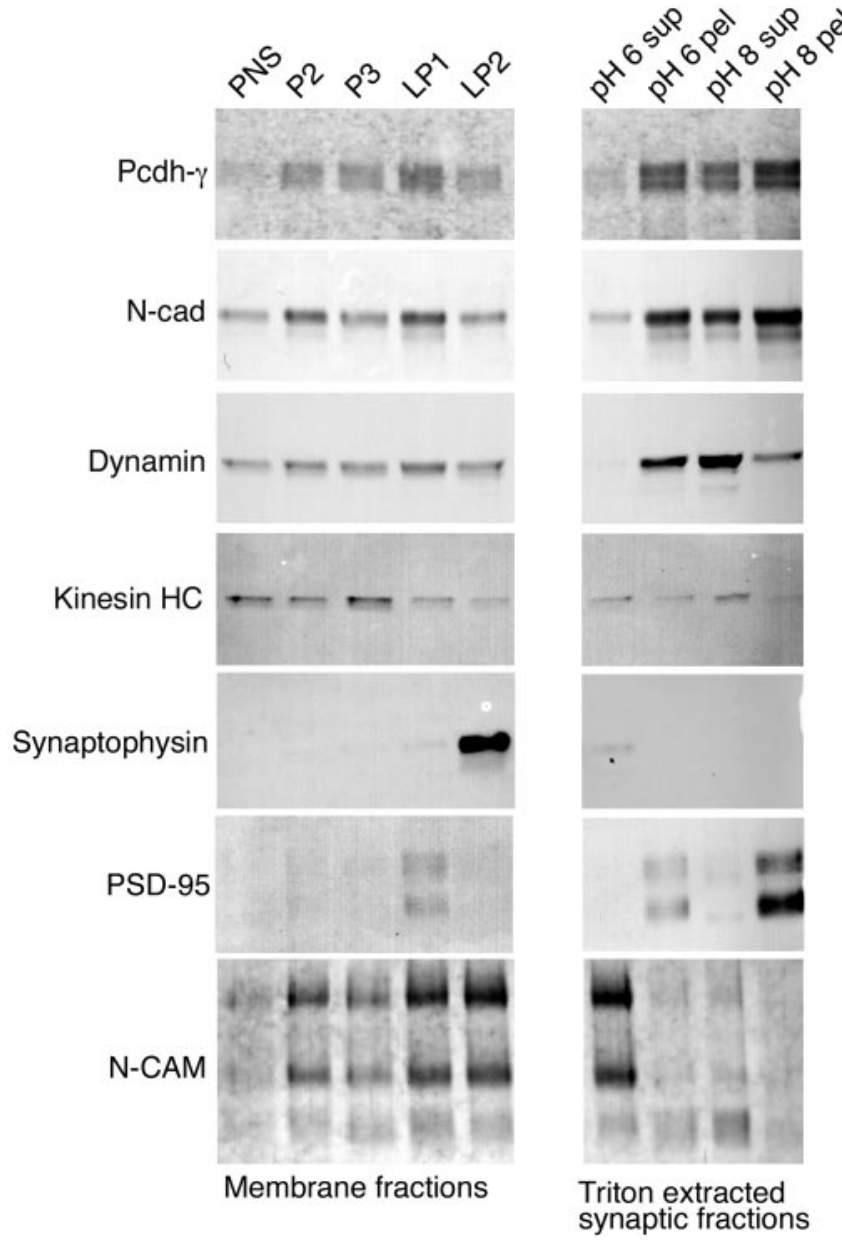

Figure 8. Pcdh- $\gamma \mathrm{s}$ cofractionate with synaptic components and intracellular membranous material. Postnuclear (PNS), crude synaptosomal (P2), large tubulovesicular organelles (P3), osmotically shocked synaptosomes (LP1), and synaptic vesicles (LP2) were prepared from adult cortices (Huttner et al., 1983). Triton-extracted nonsynaptic (pH 6 sup), intact junctional (pH 6 pel), presynaptic (pH 8 sup), and postsynaptic ( $\mathrm{pH} 8$ pel) fractions were generated using the LP1 fraction as starting material (Phillips et al., 2001). Pcdh- $\gamma$ s were enriched in the LP1 fraction relative to PNS starting material, indicating a synaptic association of these molecules. They were also found within the P3 fraction and, to a lesser extent, in the LP2 fraction. In contrast, synaptophysin was enriched in the LP2 fraction, and the kinesin heavy chain was enriched in the P3 fraction. When $L P 1$ was sequentially Triton extracted, $P$ cdh- $\gamma$ originally found in intact synaptic junctions ( $\mathrm{pH} 6$ pel) was divided into presynaptic and postsynaptic fractions containing Pcdh$\gamma \mathrm{s}$. In contrast, synaptic junctional dynamin was found primarily in the presynaptic fraction, whereas PSD-95 was found primarily in the postsynaptic fraction. N-CAM was mostly found in the nonsynaptic fraction ( $\mathrm{pH} 6$ sup) originally derived from synaptic membranes.

ecules are homophilic or heterophilic molecules is unknown (Obata et al., 1995). The classical cadherins are generally homophilic adhesion molecules, but some reports have shown that certain classical cadherins can interact heterophilically, although the strength of heterophilic interactions appears to be weaker than that of homophilic interactions (Shimoyama et al., 2000). The specificity of cadherin-based cell adhesion cannot be predicted from primary sequence alone, because the residues required for selective adhesion of classical cadherins map to a broad surface on the first extracellular domain of the classical cadherins (Shapiro et al., 1995). However, the large number of Pcdh molecules suggests that these proteins are homophilic, or at least selectively heterophilic. Our data showing that Pcdh- $\gamma$ s are not found at every excitatory synapse and that their synaptic localiza- tion is increased in Pcdh- $\gamma$-positive excitatory neuron pairs in cultures are consistent with the hypothesis that these molecules are homophilic molecules in that they may be unable to form trans-synaptic linkages at some synapses because the appropriate "matching" Pcdh- $\gamma$ is not displayed on presynaptic and postsynaptic membrane surfaces.

Multiple families of adhesion proteins contribute to the formation of a transcellular scaffold at synapses that is stable and resistant to detergent solubilization (Phillips et al., 2001). Our studies showing existing synaptic junctions in the absence of Pcdh- $\gamma$ s suggest that these molecules may not be strictly "structural" adhesive molecules required to hold synaptic membranes together. It may be that one or a combination of molecules such as the classical cadherins (Tanaka et al., 2000), the neurexins and neuroligins (Scheiffele et al., 2000), the nectins (Mizoguchi et al., 2002), or the ephrins and Eph receptors (Dalva et al., 2000; Takasu et al., 2002) form a "generic" synaptic adhesive scaffold, present at most if not all synaptic junctions, which holds the basic and required synaptic machinery on both sides of the synaptic cleft in alignment. These adhesion molecule families appear to interact with or regulate the basic machinery known to be present in most if not all excitatory synapses. For example, events in synaptogenesis, including the organization of synaptic vesicles and postsynaptic densities, were disrupted by agents that disturb the formation of a classical cadherin trans-synaptic linkage (Togashi et al., 2002) or neurexin/neuroligin interactions (Scheiffele et al., 2000), and clustering of NMDA receptors and recruitment of other synaptic components was shown to involve ephrin/EphB receptor interactions (Dalva et al., 2000; Takasu et al., 2002). Thus, unlike the Pcdh- $\gamma \mathrm{s}$, and possibly all Pcdhs, at least some of the above-mentioned molecules may be absolutely necessary for assembly of the trans-synaptic adhesive scaffold. The concept that Pcdhs are "late" modifiers of CNS synapses is supported by the recent finding that after targeted deletion of the Pcdh- $\gamma$ locus in mice, which causes embryonic degeneration and apoptosis, synaptic junctions are clearly formed with abundant and correctly localized synaptic vesicles and presynaptic and postsynaptic densities (Wang et al., 2002b).

The differential expression of Pcdhs in neurons (Kohmura et al., 1998; Wang et al., 2002b), their proposed homophilic adhesive activity, their localization at subsets of synapses and intracellular compartments, and their requirement for postnatal neural development (Wang et al., 2002b) suggest a model for the Pcdhs as modifiers of certain synaptic connections. In this model, Pcdhs are actively sorted in neurons among endosomal compartments and plasma membranes. If Pcdhs are primarily homophilic molecules (as the divergence in their extracellular domains would suggest), then a Pcdh trans-synaptic linkage could only be formed at synapses between two cells that express the same Pcdh. Many synapses would not contain a Pcdh linkage because two neurons forming a synapse may not express adhesively compatible Pcdhs (Wang et al., 2002b). As a consequence of the formation of a homophilic interaction at a synapse, Pcdhs recruited to the junction may also recruit other signaling or structural components via interactions with their constant cytoplasmic domains. Thus, it is tempting to speculate that the Pcdhs may specify a certain subset of synaptic connections formed only among cells that only express the same Pcdh. A Pcdh "marked" synapse would therefore contain additional components and possibly exhibit different physiology or stability, relative to those that do not contain Pcdhs. 


\section{References}

Aberle H, Schwartz H, Kemler R (1996) Cadherin-catenin complex: protein interactions and their implications for cadherin function. J Cell Biochem 61:514-523.

Benson DL, Tanaka H (1998) N-cadherin redistribution during synaptogenesis in hippocampal neurons. J Neurosci 18:6892-6904.

Benson DL, Watkins FH, Steward O, Banker G (1994) Characterization of GABAergic neurons in hippocampal cell cultures. J Neurocytol 23:279-295.

Bozdagi O, Shan W, Tanaka H, Benson DL, Huntley GW (2000) Increasing numbers of synaptic puncta during late-phase LTP: N-cadherin is synthesized, recruited to synaptic sites, and required for potentiation. Neuron 28:245-259.

Brunig I, Suter A, Knuesel I, Luscher B, Fritschy JM (2002) GABAergic terminals are required for postsynaptic clustering of dystrophin but not of $\operatorname{GABA}(\mathrm{A})$ receptors and gephyrin. J Neurosci 22:4805-4813.

Cantallops I, Cline HT (2000) Synapse formation: if it looks like a duck and quacks like a duck. Curr Biol 10:R620-623.

Cho KO, Hunt CA, Kennedy MB (1992) The rat brain postsynaptic density fraction contains a homolog of the Drosophila discs-large tumor suppressor protein. Neuron 9:929-942.

Cooney JR, Hurlburt JL, Selig DK, Harris KM, Fiala JC (2002) Endosomal compartments serve multiple hippocampal dendritic spines from a widespread rather than a local store of recycling membrane. J Neurosci 22:2215-2224.

Craig AM, Blackstone CD, Huganir RL, Banker G (1994) Selective clustering of glutamate and gamma-aminobutyric acid receptors opposite terminals releasing the corresponding neurotransmitters. Proc Natl Acad Sci USA 91:12373-12377.

Dalva MB, Takasu MA, Lin MZ, Shamah SM, Hu L, Gale NW, Greenberg ME (2000) EphB receptors interact with NMDA receptors and regulate excitatory synapse formation. Cell 103:945-956.

Fannon AM, Colman DR (1996) A model for central synaptic junctional complex formation based on the differential adhesive specificities of the cadherins. Neuron 17:423-434.

Huttner WB, Schiebler W, Greengard P, De Camilli P (1983) Synapsin I (protein I), a nerve terminal-specific phosphoprotein. III. Its association with synaptic vesicles studied in a highly purified synaptic vesicle preparation. J Cell Biol 96:1374-1388.

Inoue A, Sanes JR (1997) Lamina-specific connectivity in the brain: regulation by N-cadherin, neurotrophins, and glycoconjugates. Science 276:1428-1431.

Kamiguchi H, Lemmon V (2000) Recycling of the cell adhesion molecule L1 in axonal growth cones. J Neurosci 20:3676-3686.

Kanaani J, el-Husseini Ael D, Aguilera-Moreno A, Diacovo JM, Bredt DS, Baekkeskov S (2002) A combination of three distinct trafficking signals mediates axonal targeting and presynaptic clustering of GAD65. J Cell Biol 158:1229-1238.

Kohmura N, Senzaki K, Hamada S, Kai N, Yasuda R, Watanabe M, Ishii H, Yasuda M, Mishina M, Yagi T (1998) Diversity revealed by a novel family of cadherins expressed in neurons at a synaptic complex. Neuron 20:1137-1151.

Lee SH, Valtschanoff JG, Kharazia VN, Weinberg R, Sheng M (2001) Biochemical and morphological characterization of an intracellular membrane compartment containing AMPA receptors. Neuropharmacology 41:680-692.

Mizoguchi A, Nakanishi H, Kimura K, Matsubara K, Ozaki-Kuroda K, Katata T, Honda T, Kiyohara Y, Heo K, Higashi M, Tsutsumi T, Sonoda S, Ide C, Takai Y (2002) Nectin: an adhesion molecule involved in formation of synapses. J Cell Biol 156:555-565.

Nishimura W, Yao I, Iida J, Tanaka N, Hata Y (2002) Interaction of synaptic scaffolding molecule and $\beta$-catenin. J Neurosci 22:757-765.
Obata S, Sago H, Mori N, Rochelle JM, Seldin MF, Davidson M, St John T, Taketani S, Suzuki ST (1995) Protocadherin Pcdh2 shows properties similar to, but distinct from, those of classical cadherins. J Cell Sci 108:3765-3773.

Parton RG, Simons K, Dotti CG (1992) Axonal and dendritic endocytic pathways in cultured neurons. J Cell Biol 119:123-137.

Phillips GR, Huang JK, Wang Y, Tanaka H, Shapiro L, Zhang W, Shan WS, Arndt K, Frank M, Gordon RE, Gawinowicz MA, Zhao Y, Colman DR (2001) The presynaptic particle web: ultrastructure, composition, dissolution, and reconstitution. Neuron 32:63-77.

Scheiffele P, Fan J, Choih J, Fetter R, Serafini T (2000) Neuroligin expressed in nonneuronal cells triggers presynaptic development in contacting axons. Cell 101:657-669.

Scotti AL, Herrmann G (2002) Reelin immunoreactivity in dissociated cultures of the postnatal hippocampus. Brain Res 924:209-218.

Senzaki K, Ogawa M, Yagi T (1999) Proteins of the CNR family are multiple receptors for Reelin. Cell 99:635-647.

Shapiro L, Fannon AM, Kwong PD, Thompson A, Lehmann MS, Grubel G, Legrand JF, Als-Nielsen J, Colman DR, Hendrickson WA (1995) Structural basis of cell-cell adhesion by cadherins. Nature 374:327-337.

Shimoyama Y, Tsujimoto G, Kitajima M, Natori M (2000) Identification of three human type-II classic cadherins and frequent heterophilic interactions between different subclasses of type-II classic cadherins. Biochem J 349:159-167.

Takasu MA, Dalva MB, Zigmond RE, Greenberg ME (2002) Modulation of NMDA receptor-dependent calcium influx and gene expression through EphB receptors. Science 295:491-495.

Tanaka H, Shan W, Phillips GR, Arndt K, Bozdagi O, Shapiro L, Huntley GW, Benson DL, Colman DR (2000) Molecular modification of N-cadherin in response to synaptic activity. Neuron 25:93-107.

Tasic B, Nabholz CE, Baldwin KK, Kim Y, Rueckert EH, Ribich SA, Cramer P, Wu Q, Axel R, Maniatis T (2002) Promoter choice determines splice site selection in protocadherin alpha and gamma pre-mRNA splicing. Mol Cell 10:21-33.

Togashi H, Abe K, Mizoguchi A, Takaoka K, Chisaka O, Takeichi M (2002) Cadherin regulates dendritic spine morphogenesis. Neuron 35:77-89.

Uchida N, Honjo Y, Johnson KR, Wheelock MJ, Takeichi M (1996) The catenin/cadherin adhesion system is localized in synaptic junctions bordering transmitter release zones. J Cell Biol 135:767-779.

van Lookeren Campagne M, Oestreicher AB, van der Krift TP, Gispen WH, Verkleij AJ (1991) Freeze-substitution and Lowicryl HM20 embedding of fixed rat brain: suitability for immunogold ultrastructural localization of neural antigens. J Histochem Cytochem 39:1267-1279.

Wang X, Su H, Bradley A (2002a) Molecular mechanisms governing Pcdhgamma gene expression: evidence for a multiple promoter and cisalternative splicing model. Genes Dev 16:1890-1905.

Wang X, Weiner JA, Levi S, Craig AM, Bradley A, Sanes JR (2002b) Gamma protocadherins are required for survival of spinal interneurons. Neuron 36:843-854.

Wu Q, Maniatis T (1999) A striking organization of a large family of human neural cadherin-like cell adhesion genes. Cell 97:779-790.

Wu Q, Zhang T, Cheng JF, Kim Y, Grimwood J, Schmutz J, Dickson M, Noonan JP, Zhang MQ, Myers RM, Maniatis T (2001) Comparative DNA sequence analysis of mouse and human protocadherin gene clusters. Genome Res 11:389-404.

Yamagata M, Herman JP, Sanes JR (1995) Lamina-specific expression of adhesion molecules in developing chick optic tectum. J Neurosci 15: $4556-4571$.

Zhai RG, Vardinon-Friedman H, Cases-Langhoff C, Becker B, Gundelfinger ED, Ziv NE, Garner CC (2001) Assembling the presynaptic active zone. A characterization of an active zone precursor vesicle. Neuron 29:131-143. 